\title{
A new global grid-based weighted mean temperature model considering vertical nonlinear variation
}

\author{
Peng Sun ${ }^{1}$, Suqin Wu ${ }^{1,2}$, Kefei Zhang ${ }^{1,2}$, Moufeng Wan ${ }^{1}$, and Ren Wang ${ }^{1}$ \\ ${ }^{1}$ School of Environment Science and Spatial Informatics, China University of Mining and Technology, Xuzhou 221116, China \\ ${ }^{2}$ SPACE Research Center, School of Science, RMIT University, Melbourne 3001, Australia
}

Correspondence: Suqin Wu (sue.wu2018@gmail.com)

Received: 8 July 2020 - Discussion started: 7 October 2020

Revised: 12 February 2021 - Accepted: 19 February 2021 - Published: 31 March 2021

\begin{abstract}
Global navigation satellite systems (GNSS) have been proved to be an excellent technology for retrieving precipitable water vapor (PWV). In GNSS meteorology, PWV at a station is obtained from a conversion of the zenith wet delay (ZWD) of GNSS signals received at the station using a conversion factor which is a function of weighted mean temperature $\left(T_{\mathrm{m}}\right)$ along the vertical direction in the atmosphere over the site. Thus, the accuracy of $T_{\mathrm{m}}$ directly affects the quality of the GNSS-derived PWV. Currently, the $T_{\mathrm{m}}$ value at a target height level is commonly modeled using the $T_{\mathrm{m}}$ value at a specific height and a simple linear decay function, whilst the vertical nonlinear variation in $T_{\mathrm{m}}$ is neglected. This may result in large errors in the $T_{\mathrm{m}}$ result for the target height level, as the variation trend in the vertical direction of $T_{\mathrm{m}}$ may not be linear. In this research, a new global grid-based $T_{\mathrm{m}}$ empirical model with a horizontal resolution of $1^{\circ} \times 1^{\circ}$, named GGNTm, was constructed using ECMWF ERA5 monthly mean reanalysis data over the 10 -year period from 2008 to 2017. A three-order polynomial function was utilized to fit the vertical nonlinear variation in $T_{\mathrm{m}}$ at the grid points, and the temporal variation in each of the four coefficients in the $T_{\mathrm{m}}$ fitting function was also modeled with the variables of the mean, annual, and semiannual amplitudes of the 10-year time series coefficients. The performance of the new model was evaluated using its predicted $T_{\mathrm{m}}$ values in 2018 to compare with the following two references in the same year: (1) $T_{\mathrm{m}}$ from ERA5 hourly reanalysis with the horizontal resolution of $5^{\circ} \times 5^{\circ}$; (2) $T_{\mathrm{m}}$ from atmospheric profiles from 428 globally distributed radiosonde stations. Compared to the first reference, the mean RMSEs of the model-predicted $T_{\mathrm{m}}$ values over all global grid points at the 950 and $500 \mathrm{hPa}$ pressure levels were 3.35
\end{abstract}

and $3.94 \mathrm{~K}$, respectively. Compared to the second reference, the mean bias and mean RMSE of the model-predicted $T_{\mathrm{m}}$ values over the 428 radiosonde stations at the surface level were 0.34 and $3.89 \mathrm{~K}$, respectively; the mean bias and mean RMSE of the model's $T_{\mathrm{m}}$ values over all pressure levels in the height range from the surface to $10 \mathrm{~km}$ altitude were -0.16 and $4.20 \mathrm{~K}$, respectively. The new model results were also compared with that of the GTrop and GWMT_D models in which different height correction methods were also applied. Results indicated that significant improvements made by the new model were at high-altitude pressure levels; in all five height ranges, GGNTm results were generally unbiased, and their accuracy varied little with height. The improvement in PWV brought by GGNTm was also evaluated. These results suggest that considering the vertical nonlinear variation in $T_{\mathrm{m}}$ and the temporal variation in the coefficients of the $T_{\mathrm{m}}$ model can significantly improve the accuracy of model-predicted $T_{\mathrm{m}}$ for a GNSS receiver that is located anywhere below the tropopause (assumed to be $10 \mathrm{~km}$ ), which has significance for applications requiring real-time or near real-time PWV converted from GNSS signals.

\section{Introduction}

Water vapor, as an important greenhouse gas, is closely related to weather variations; hence, it is crucial to monitor the water vapor content in the atmosphere for a reliable weather forecast. The meteorological parameter that is closely related to water vapor is precipitable water vapor (PWV) and it can be measured by various technologies such as radiosondes, remote-sensing satellites, and water vapor radiometers. 
Global navigation satellite systems (GNSS), which were initially designed for positioning, navigation, and timing, can be used to retrieve the zenith tropospheric delay (ZTD) of the GNSS signal over an observation station. The ZTD can be divided into zenith hydrostatic delay (ZHD) and zenith wet delay (ZWD). The ZHD can usually be obtained at a high accuracy from the Saastamoinen model together with measured meteorological data at the station. The atmospheric water vapor information is contained in the GNSS-ZTD more precisely, in the GNSS-ZWD - which can be converted into PWV. Different from the other atmospheric measurement techniques, GNSS receivers are regarded as costeffective equipment for meteorological research; the main advantage of the GNSS-based method is its real-time, stable, high temporal-resolution, and relative long-term capabilities. The GNSSs were first applied to meteorological research in the 1990s (Bevis et al., 1992). Some preliminary research in relation to the long-term feature of the GNSS-ZTD/PWV series and the relationship between GNSS-PWV and weather or climate issues has already been carried out (Bianchi et al., 2016; Bonafoni and Biondi, 2016; Calori et al., 2016; Chen et al., 2018; Choy et al., 2013; He et al., 2019; Shi et al., 2015; Rohm et al., 2014a; Wang et al., 2016, 2018; Zhang et al., 2015). Near real-time GNSS-ZTD products estimated from GNSS data processing have been routinely assimilated into numerical weather models (NWMs) for improving the performance of weather forecasts (Bennitt and Jupp, 2012; Dousa and Vaclavovic, 2014; Guerova et al., 2016; Le Marshall et al., 2012, 2019).

To obtain GNSS-PWV over a station, the first step is to estimate the ZTD of the station from GNSS data processing, and the two most common data processing strategies are the network approach and precise point positioning (PPP) approach (Ding et al., 2017; Douša et al., 2016; Guerova et al., 2016; Li et al., 2015; Lu et al., 2015; Rohm et al., 2014b; Yuan et al., 2014; Zhou et al., 2020). The former uses doubledifferenced observations, while the latter uses un-differenced observations in the observation equation system. The ZWD can be obtained from subtracting the ZHD from the GNSSZTD or directly estimated if the ZHD has been corrected in the GNSS observation equation system, depending on the processing strategies adopted. Then the GNSS-PWV can be converted by

$\mathrm{PWV}=\Pi \times \mathrm{ZWD}$,

where $\Pi$ is the conversion factor (Askne and Nordius, 1987; Bevis et al., 1992), which is given by

$\Pi=\frac{10^{6}}{\rho_{\mathrm{w}} R_{\mathrm{v}}\left(\frac{k_{3}}{T_{\mathrm{m}}}+k_{2}^{\prime}\right)}$,

where $\rho_{\mathrm{W}}$ is the density of liquid water; $R_{\mathrm{V}}=$ $461.5 \mathrm{~J} /(\mathrm{kg} \times \mathrm{K})$ is the specific gas constant for water vapor; $k_{2}^{\prime}=22.1 \mathrm{~K} / \mathrm{hPa}$ and $k_{3}=373900 \mathrm{~K}^{2} / \mathrm{hPa}$ are atmospheric refractivity constants; $T_{\mathrm{m}}$ is the weighted mean temperature over the GNSS site, which is defined and approximated through the following equation (Davis et al., 1985):

$T_{\mathrm{m}}=\frac{\int \frac{e}{T} \mathrm{~d} h}{\int \frac{e}{T^{2}} \mathrm{~d} h} \approx \frac{\sum_{1}^{n} \frac{\overline{e_{i}}}{\overline{T_{i}}} \Delta h_{i}}{\sum_{1}^{n} \frac{\overline{e_{i}}}{\bar{T}_{i}^{2}} \Delta h_{i}}$,

where $e$ and $T$ are the water vapor pressure (hPa) and absolute temperature $(\mathrm{K})$, respectively; $n$ is the number of the layers; $\overline{e_{i}}, \overline{T_{i}}$, and $\Delta h_{i}$ are the mean water vapor pressure, mean temperature, and thickness of the $i$ th layer, respectively.

From Eq. (2), one can see that $T_{\mathrm{m}}$ is a crucial variable for the determination of the conversion factor $\Pi$, which in turn affects the determination of PWV expressed by Eq. (1). The significance of obtaining accurate $T_{\mathrm{m}}$ values has been demonstrated by previous research (Bevis, 1994; Jiang et al., 2019a; Ning et al., 2016; Wang et al., 2005, 2016). $T_{\mathrm{m}}$ can be calculated from an observed atmospheric profile. This observed atmospheric profile can be acquired from a radiosonde station, which is valid only for the sounding site. In fact, for GNSS stations, they are usually not co-located with any regional radiosonde stations; i.e., observed atmospheric profiles are unavailable. As a result, Eq. (3) is not applicable for GNSS stations. Moreover, even if a GNSS station is colocated with a radiosonde station, due to the low temporal and spatial resolution of radiosonde data, the temporal resolution of its resultant $T_{\mathrm{m}}$ is also low, which cannot meet the requirements of GNSS near real-time or real-time (NRT/RT) applications such as the conversion of GNSS-ZWD time series into PWV time series. The atmospheric profiles from NWM data can be obtained for $T_{\mathrm{m}}$ determination (Wang et al., 2005, 2016). However, for some time-critical applications, NRT/RT $T_{\mathrm{m}}$ is essential for NRT/RT GNSS-PWV determination; thus the main drawback in using the reanalysis data is its latency issue, and it is still difficult for most users to obtain predicted results to obtain from the NWM data. Thus, it is of great importance to develop empirical $T_{\mathrm{m}}$ models for time-critical applications. Some $T_{\mathrm{m}}$ models have been developed with a focus of improving the accuracy of the $T_{\mathrm{m}}$, and these empirical models can be classified into two categories. One category is such a model that depends on in situ surface temperature observation $T_{\mathrm{s}}$, like the Bevis model, which is a simple linear function expressed as $T_{\mathrm{m}}=a+b T_{\mathrm{S}}$ (Bevis et al., 1992). The two coefficients of such a linear function can be determined from the linear regression method based on long-term regional radiosonde data. However, the deployment of radiosonde stations is geographically sparse due to their high cost, and it is even worse that there are no radiosonde stations at all in some areas. One of the possible ways to solve the availability issue is to use reanalysis data to develop $T_{\mathrm{m}}-T_{\mathrm{s}}$ models. However, such a reanalysis-based $T_{\mathrm{m}}-T_{\mathrm{s}}$ model may not be as accurate as that derived from local radiosonde profiles. Yao et al. (2014a) developed a global latitude-dependent $T_{\mathrm{m}}-T_{\mathrm{S}}$ linear model using $T_{\mathrm{m}}$ data from the global geodetic observing system (GGOS) and $T_{\mathrm{S}}$ data 
from the European center for medium-range weather forecasts (ECMWF). Jiang developed a time-varying global gridded $T_{\mathrm{m}}-T_{\mathrm{s}}$ model using both $T_{\mathrm{m}}$ and $T_{\mathrm{s}}$ derived from ERAInterim (Jiang et al., 2019a). Ding (2018, 2020) developed two generations of global $T_{\mathrm{m}}$ models using the neural network algorithm, in which temperature observations were required for the input and the models performed well. The $T_{\mathrm{m}}$ models mentioned above need in situ meteorological observations (mainly $T_{\mathrm{S}}$ ) as the model's input. However, for GNSS stations, not all stations are equipped with meteorological sensors. Although the meteorological parameters at the user station can also be interpolated using the actual meteorological measurements nearby, the interpolation error depends on the terrain difference between the meteorological sensor's location and the point of interest in addition the interpolation methods used.

To address the above-mentioned issues, the type of empirical models that are independent of meteorological observations had to be constructed. Yao et al. (2014b, 2012, 2013) used spherical harmonics to develop the GWMT, GTM-II, and GTM-III models, in which both the height and the periodicity of $T_{\mathrm{m}}$ were taken into account. Huang et al. (2019a) established a global $T_{\mathrm{m}}$ model using the sliding window algorithm, which was based on varying latitude and altitude. The widely used GPT2w model (Böhm et al., 2015) and its successor, GPT3 (Landskron and Böhm, 2018), provided gridded results with both $1^{\circ} \times 1^{\circ}$ and $5^{\circ} \times 5^{\circ}$ horizontal resolutions, and the models also contain a few terms related to temporal variations in $T_{\mathrm{m}}$ including the mean, annual, and semi-annual amplitudes. However, the height differences between the user site, e.g., a GNSS station, and its nearest four surrounding grid points were not considered. Recent studies have overcome this problem by providing $T_{\mathrm{m}}$ values at various heights ranging from ground surface to the upper troposphere. He et al. (2017) developed a voxel-based global model, named GWMT-D, using the $T_{\mathrm{m}}$ values at four height levels of reanalysis data from the National Centers for Environmental Prediction (NCEP) to construct the voxels. The $T_{\mathrm{m}}$ predicted for the user site can be obtained from an interpolation of the $T_{\mathrm{m}}$ values at the eight grid points of the voxel that contains the user site. In recent studies, some researchers used a $T_{\mathrm{m}}$ lapse rate, the rate of change in $T_{\mathrm{m}}$ with altitude, to correct the effect of the height element on $T_{\mathrm{m}}$, e.g., IGPT2w (Huang et al., 2019b), GTm_R (Li et al., 2020), and GPT2wh (Yang et al., 2020). The GTrop model (Sun et al., 2019), developed for predicting both ZTD and $T_{\mathrm{m}}$, also took into account the $T_{\mathrm{m}}$ lapse rate, and it outperforms GPT2w obviously at altitudes under $10 \mathrm{~km}$.

We have noticed that some studies have extended the GNSS-PWV sensing to a shipborne GNSS receiver or GNSS receiver that is onboard other moving vehicles (Fan et al., 2016; Wang et al., 2019; Webb et al., 2016). Thus, we concentrated on developing a high-accuracy unbiased empirical model for predicting $T_{\mathrm{m}}$ values in any possible places, which is meaningful for GNSS meteorology. As previously
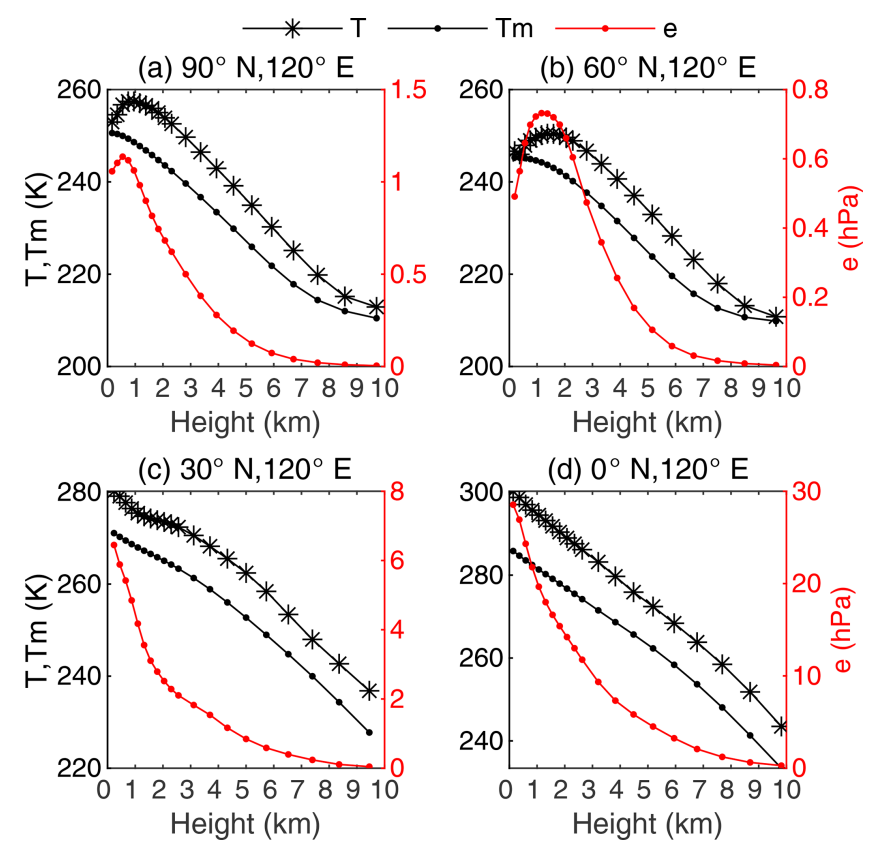

Figure 1. Temperature $T$, water vapor pressure $e$, and $T_{\mathrm{m}}$ profiles obtained from ERA5 monthly mean reanalysis in December 2017 at four grid points: (a) $90^{\circ} \mathrm{N}, 120^{\circ} \mathrm{E}$; (b) $60^{\circ} \mathrm{N}, 120^{\circ} \mathrm{E}$; (c) $30^{\circ} \mathrm{N}$, $120^{\circ} \mathrm{E} ;$ (d) $0^{\circ} \mathrm{N}, 120^{\circ} \mathrm{E}$.

discussed, considering the lapse rate in a $T_{\mathrm{m}}$ model can improve the model's accuracy. However, the assumption that $T_{\mathrm{m}}$ linearly varies with height, which many recently developed models were based on, may not agree well with the truth. In this research, a new global grid-based empirical $T_{\mathrm{m}}$ model, named GGNTm, in which the vertical nonlinear variation in $T_{\mathrm{m}}$ was taken into account, was developed using a three-order polynomial function and ERA5 monthly mean reanalysis data over the 10-year period from 2008 to 2017 , and the temporal variation in each of the four coefficients in the $T_{\mathrm{m}}$ fitting function was also modeled with the variables of the mean, annual, and semi-annual amplitudes of the 10-year time series coefficient.

The outline of the paper is as follows. The features of the vertical nonlinear variation in $T_{\mathrm{m}}$ were investigated in Sect. 2.2; then a three-order polynomial function fitting the 10-year $T_{\mathrm{m}}$ profiles obtained from ERA-5 monthly mean reanalysis data was developed for the GGNTm model. In Sect. 3, the performance of GGNTm was validated using the $T_{\mathrm{m}}$ values from ERA5 hourly reanalysis and globally distributed radiosonde profiles in 2018 as the references. Conclusions are summarized in the final section. 

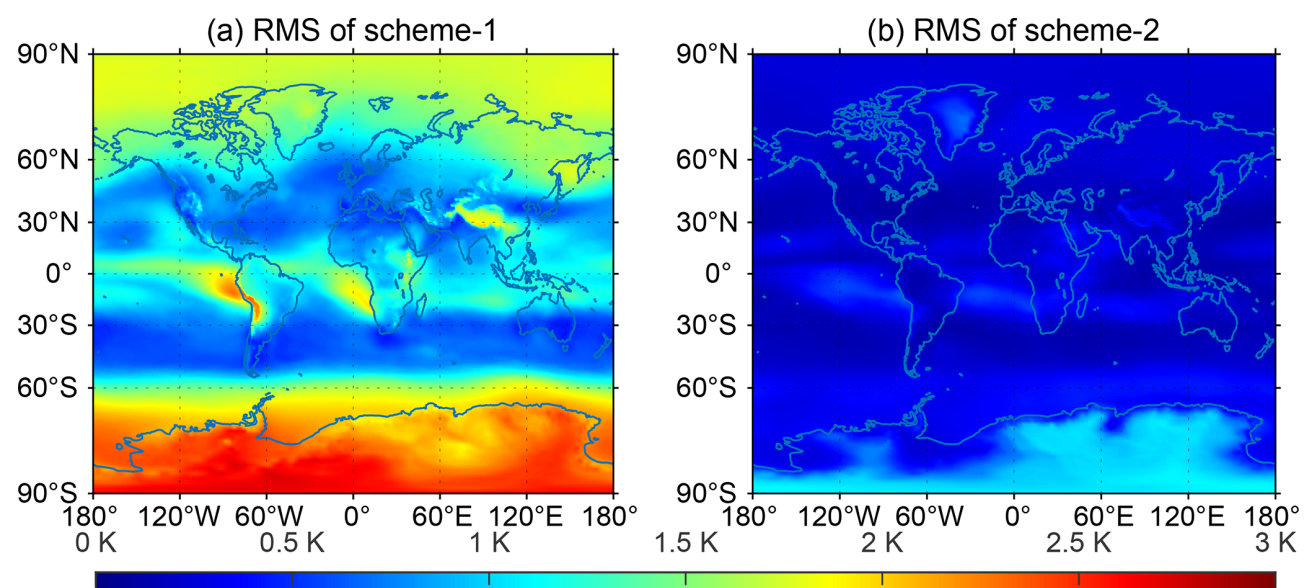

Figure 2. Mean of rms's of the $T_{\mathrm{m}}$ residuals of 120 monthly mean profiles from the 10-year period at each grid point for scheme 1 (a, for linear function) and scheme 2 (b, for three-order polynomial function).

\section{Methodology for new model construction}

\subsection{Data source}

ERA5 reanalysis data were the latest reanalysis data developed by the ECMWF. In this research, ERA5 monthly mean reanalysis data in the 10-year period from 2008 to 2017 containing geopotential heights, temperatures, and specific humidity at 37 pressure levels with a horizontal resolution of $1^{\circ} \times 1^{\circ}$ were downloaded from the web server of the Copernicus Climate Change Service (C3S). The geopotential heights, which are often used in meteorology, were then converted to WGS-84 ellipsoidal heights. Water vapor pressure was calculated by (Nafisi et al., 2012)

$e=q p /(0.622+0.378 q)$,

where $q$ is the specific humidity, which can be obtained from NWM data; $p$ is the atmospheric pressure.

\subsection{Vertical variation in $T_{\mathrm{m}}$}

The ERA5 monthly mean products were used to analyze the vertical variation in $T_{\mathrm{m}}$. As defined in Eq. (3), $T_{\mathrm{m}}$ is a function of water vapor pressure and temperature. The variation in water vapor pressure in the vertical direction has been known to be nonlinear, while the vertical variation in temperature is often assumed to be a linear decay function (Dousa and Elias, 2014). In fact, there is such a phenomenon that temperature increases with the increase in height, the socalled temperature inversion, which occurs in both the upper atmosphere and near ground surface, meaning that the vertical variation in temperature is complex. As a result, $T_{\mathrm{m}}$ in the vertical direction varies nonlinearly due to the irregular variations in both water vapor pressure and temperature in the vertical direction. Figure 1 shows four vertical profiles of water vapor pressure, temperature, and $T_{\mathrm{m}}$ at the pressure levels that were under a $10 \mathrm{~km}$ ellipsoidal height at four grid points obtained from ERA5 monthly mean reanalysis in December 2017. It should be noted that the surface heights of the four grid points were different, and they were 0,301 , 13 , and $180 \mathrm{~m}$, respectively. Panels (a) and (b) show that, in the height range near the surface, temperature increases with the increase in height. In addition, all the four $T_{\mathrm{m}}$ profiles (the black curves with dots) in these panels show a nonlinear variation trend. This implies that using a constant lapse rate to model the vertical $T_{\mathrm{m}}$ variation trend will result in large errors; i.e., the $T_{\mathrm{m}}$ profiles cannot be accurately modeled through a constant $T_{\mathrm{m}}$ lapse rate. This finding aligns well with that of other researchers (e.g., Yao et al., 2018).

\subsection{Three-order polynomial function for $T_{\mathrm{m}}$ vertical fitting}

A linear $T_{\mathrm{m}}$ decay function with a constant $T_{\mathrm{m}}$ lapse rate can be expressed as

$T_{\mathrm{m}}=\alpha+\beta\left(H-h_{0}\right)$,

where $\alpha$ is the $T_{\mathrm{m}}$ value at the reference height $h_{0} ; \beta$ is the $T_{\mathrm{m}}$ lapse rate and $H$ is the ellipsoidal height $(\mathrm{km})$ of the user site. An equivalent expression of Eq. (5) is

$T_{\mathrm{m}}=\alpha^{\prime}+\beta^{\prime} H$,

where $\alpha^{\prime}$ denotes the $T_{\mathrm{m}}$ value at $0 \mathrm{~km}$ ellipsoidal height. Some $T_{\mathrm{m}}$ models were constructed based on this linear $T_{\mathrm{m}}$ decay function. $T_{\mathrm{m}}$ values from different height ranges can be used to calculate the $T_{\mathrm{m}}$ lapse rate. However, if $T_{\mathrm{m}}$ varies nonlinearly in the vertical direction, the calculated $T_{\mathrm{m}}$ lapserate values would have large errors. To overcome this problem, in this research, a three-order polynomial function was selected for a new $T_{\mathrm{m}}$ model:

$T_{\mathrm{m}}=a+b H+c H^{2}+d H^{3}$, 
(a) Coefficient a

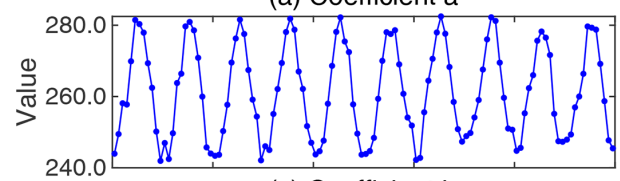

(c) Coefficient b

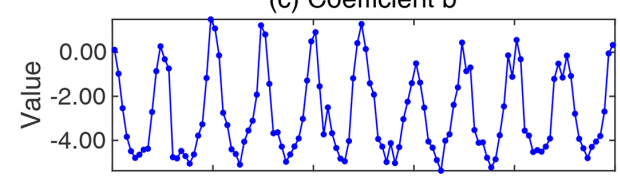

(e) Coefficient c

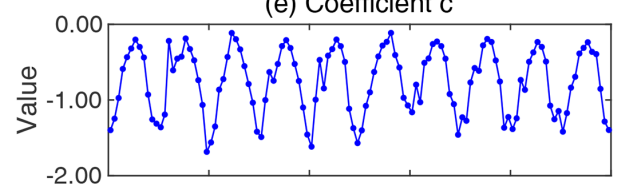

(g) Coefficient d

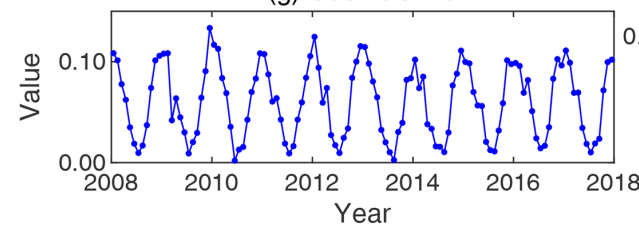

(b) Amplitude of a

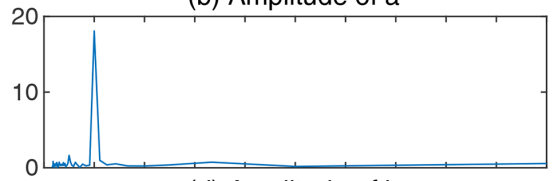

(d) Amplitude of $b$

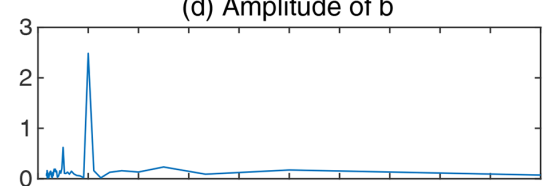

(f) Amplitude of c

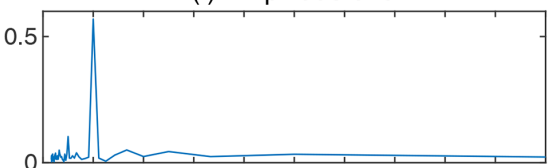

(h) Amplitude of $d$

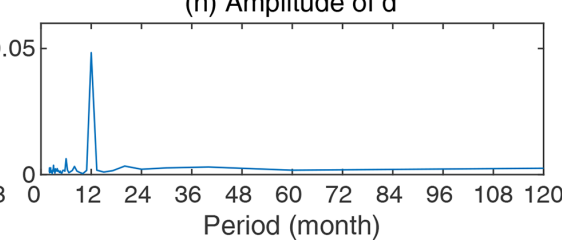

Figure 3. Periodicity reflected in the 10 -year time series of each coefficient in the three-order polynomial function at $60^{\circ} \mathrm{N}, 120^{\circ} \mathrm{E}$.

where $a, b, c, d$ are the four unknown coefficient parameters of the fitting function.

For the estimation of the two sets of unknown coefficient parameters expressed in Eqs. (6) and (7), two schemes, named scheme 1 and scheme 2 , fitted the sample data of $T_{\mathrm{m}}$ profiles of the 120 monthly mean reanalysis data over the 10year period from 2008 to 2017 at each grid point for the two functions. It should be noted that only those $T_{\mathrm{m}}$ values from heights under $10 \mathrm{~km}$ were selected for the sample data. For measuring how well the fitting function fits the sample data, the root mean square (rms) of the differences between the $T_{\mathrm{m}}$ values resulting from the fitting function and the sample data was calculated by

$\mathrm{rms}=\sqrt{\frac{1}{n} \sum_{i}^{n} \Delta_{i}^{2},}$

where $\Delta_{i}$ is the residual of $T_{\mathrm{m}}$ at the $i$ th pressure level over the grid point. Figure 2 shows the map for the mean of the rms's of the fitting residuals of the $T_{\mathrm{m}}$ from the aforementioned 120 monthly mean $T_{\mathrm{m}}$ profiles (the samples) at each of the grid points. The mean of the mean rms's at all global grid points for scheme 1 and scheme 2 were 1.26 and $0.30 \mathrm{~K}$, respectively. In addition, the rms results in panel (a) (for linear function) were latitude-dependent, and small rms's (blue) were in midlatitude regions; large rms values in both panels were in Antarctica. Comparing the two panels, we found that the rms values shown in panel (b) were all very small and significantly smaller than those of panel (a), meaning that the three-order polynomial fitting function was superior to the linear fitting function.

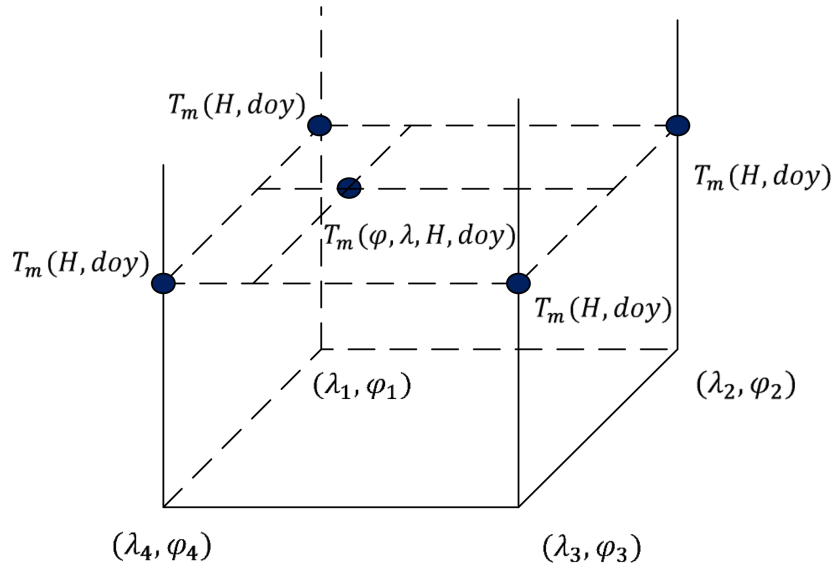

Figure 4. Spatial interpolation of the $T_{\mathrm{m}}$ value for the target point $(\varphi \lambda H)$. After obtaining the $T_{\mathrm{m}}$ values at height $H$ at the four grid points (see the four grids on the top plane) by the GGNTm model using Eq. (7), the $T_{\mathrm{m}}$ value at the target point can be interpolated (the dashed rectangle).

\section{4 $T_{\mathrm{m}}$ temporal fitting for the new model}

In the previous section, the 10-year time series of coefficients in the three-order polynomial function expressed in Eq. (7) at each of the grid points were obtained from the least-squares estimation. Since they were not constant values, the temporal variation in each coefficient at each grid point needs to be further modeled for the new grid-based empirical $T_{\mathrm{m}}$ model proposed in this study, GGNTm. The seasonal variation reflected in the 10-year time series of each of the co- 
Table 1. Mean bias and mean RMSE of $T_{\mathrm{m}}$ values at each of five pressure levels at 12:00 UTC at all global grid points in 2018 resulting from each of the three models selected.

\begin{tabular}{llrrr}
\hline Pressure level (hPa) & Statistic (K) & \multicolumn{3}{c}{ Model } \\
\cline { 3 - 5 } & & GTrop & GWMT_D & GGNTm \\
\hline 950 & & & & \\
\hline & mean bias & -0.14 & 1.68 & -0.43 \\
& mean RMSE & 3.39 & 3.98 & 3.35 \\
\hline 800 & & & & \\
\hline \multirow{5}{*}{650} & mean bias & -0.14 & 2.09 & 0.09 \\
\hline & mean RMSE & 3.79 & 4.46 & 3.77 \\
\hline 500 & mean bias & 0.76 & 1.84 & 0.15 \\
\hline & mean RMSE & 4.14 & 4.58 & 4.07 \\
\hline \multirow{5}{*}{350} & mean bias & 2.97 & 2.07 & 0.30 \\
\hline & mean RMSE & 5.17 & 4.57 & 3.94 \\
\hline & mean bias & 5.71 & 1.90 & 0.78 \\
\hline & mean RMSE & 7.12 & 3.93 & 3.02 \\
\hline
\end{tabular}

efficients $r=a, b, c, d$ was analyzed using the fast Fourier transform (FFT), and results for seasonality and periodicity at point $60^{\circ} \mathrm{N}, 120^{\circ} \mathrm{E}$ are shown in Fig. 3, which presented noticeable annual and semi-annual amplitudes. Similar periodicities were also found at other grid points. According to these characteristics, the fitting model for GGNTm containing three terms including mean, annual, and semi-annual amplitudes for each coefficient time series at each grid point expressed by the following was adopted in this study:

$r=A_{0}+A_{1} \cos \left(\frac{\mathrm{doy}-d_{1}}{365.25} 2 \pi\right)+A_{2} \cos \left(\frac{\mathrm{doy}-d_{2}}{365.25} 4 \pi\right)$,

where $A_{0}, A_{1}$, and $A_{2}$ are the mean, annual, and semi-annual amplitudes, respectively; doy denotes "day of year"; $d_{1}$ and $d_{2}$ are the initial phases of the annual and semi-annual periodicities, which are estimated together with the mean and amplitudes.

Then, the mean, annual, and semi-annual amplitudes and initial phases for each coefficient at each of the grid points over the globe (with the resolution of $1^{\circ} \times 1^{\circ}$ ) were determined using the least-squares estimation method and the 10 year time series of the coefficient. To calculate $T_{\mathrm{m}}$ for a specific site and time, e.g., for a GNSS station at an observing time, the following three-step procedure needs to be carried out:

1. use Eq. (9) to calculate each of the four coefficients at each of the four grid points surrounding the user site;
2. use Eq. (7) to calculate the $T_{\mathrm{m}}$ values at the height of the user site at each of the above four grid points (which is for the height dimension);

3. use an interpolation method, such as the inverse distance weighting or bilinear interpolation, on the four $T_{\mathrm{m}}$ values from step (2) to obtain the $T_{\mathrm{m}}$ value for the user site (which is for the horizontal dimension, as shown in Fig. 4).

Till now the new model has been developed based on the 10-year sample data from 2008 to 2017 . This model will be validated using the model-predicted $T_{\mathrm{m}}$ results in $2018 \mathrm{com}-$ pared against the same year's (i.e., out-of-sample) reference data. Results will be discussed in the next section.

\section{Evaluation of GGNTm}

For the performance assessment of our newly developed $T_{\mathrm{m}}$ model, $T_{\mathrm{m}}$ values over different pressure levels obtained from both ERA-5 hourly reanalysis (at 12:00 UTC) and globally distributed radiosonde profiles in 2018 were selected as the references. Thus, both 24 and $12 \mathrm{~h}$ variations in $T_{\mathrm{m}}$ have been contained in the reference data for the evaluation of our new model. The two statistics - bias and RMSE - were utilized to measure the systematic discrepancy and the accuracy of the 

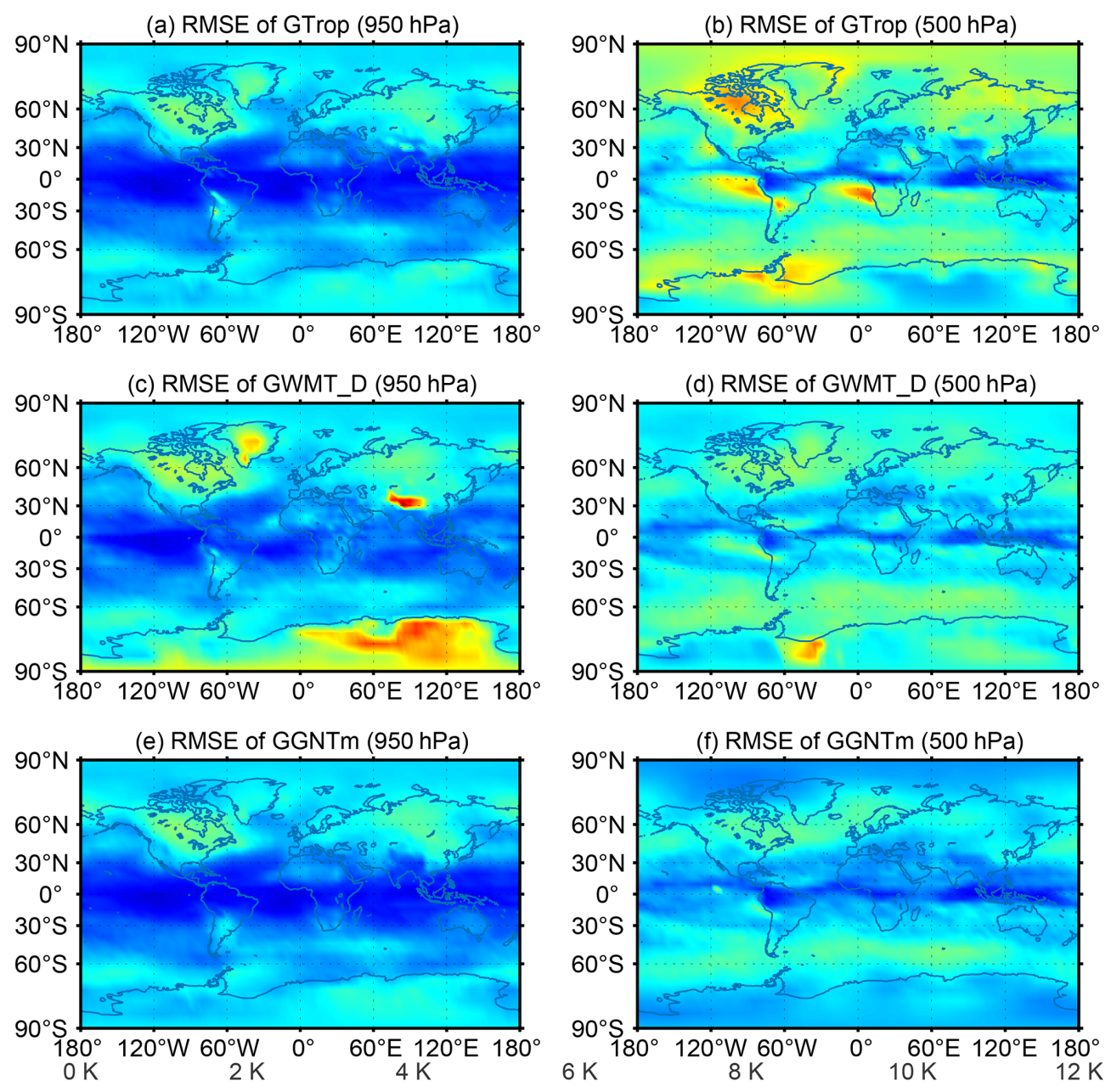

Figure 5. RMSE of $T_{\mathrm{m}}$ at each grid point at $950 \mathrm{hPa}(\mathbf{a}, \mathbf{c}, \mathbf{e})$ and $500 \mathrm{hPa}(\mathbf{b}, \mathbf{d}, \mathbf{f})$ pressure levels in 2018 resulting from GTrop, GWMT_D, and GGNTm.

model results. Their formulas are

bias $=\frac{1}{n} \sum_{i=1}^{n}\left(T_{\mathrm{m}_{i}}^{\text {model }}-T_{\mathrm{m}_{i}}^{\mathrm{ref}}\right)$,

$\mathrm{RMSE}=\sqrt{\frac{1}{n} \sum_{i=1}^{n}\left(T_{\mathrm{m}_{i}}^{\mathrm{model}}-T_{\mathrm{m}_{i}}^{\mathrm{ref}}\right)^{2}}$

where $i$ is the index of the data element; $T_{\mathrm{m}_{i}}^{\text {model }}$ denotes the model resultant $T_{\mathrm{m}}$ value; $T_{\mathrm{m}_{i}}^{\mathrm{ref}}$ denotes the reference $T_{\mathrm{m}}$ value; $n$ is the number of the $T_{\mathrm{m}}$ values in the statistics.

\subsection{Comparison with ERA5 hourly data}

As the first set of the reference selected for the evaluation of the new model, ERA-5 hourly data (with the resolution of $5^{\circ} \times 5^{\circ}$ ) at 12:00 UTC on each day in 2018, which were outof-sample data, were downloaded from the C3S. Then they were converted to $T_{\mathrm{m}}$ profiles and $T_{\mathrm{m}}$ values at each of five pressure levels: $950,800,650,500$, and $350 \mathrm{hPa}$ were used to calculate the bias and RMSE of the new model's $T_{\mathrm{m}}$ results at the pressure level. In addition to the GGNTm model, the other two empirical models developed in recent years including GTrop and GWMT_D, in which different vertical correction methods were also applied, were also evaluated for performance comparisons of GGNTm and these two models.

Table 1 shows the mean bias and mean RMSE of the $T_{\mathrm{m}}$ values over all global grid points resulting from each of the above three models. As we can see, on a global scale, GGNTm outperformed all the other two models, especially at high pressure levels. The GTrop has been proved to be considerably better than GPT3 (Sun et al., 2019), owing to its use of the $T_{\mathrm{m}}$ lapse rate, although its $T_{\mathrm{m}}$ results still had large errors at high pressure levels, which is most likely to result from neglecting the nonlinear vertical variation in $T_{\mathrm{m}}$. The large bias and RMSE of the GWMT_D results were possibly because its modeling was based on NCEP reanalysis data, and there may exist differences between the reanalysis 

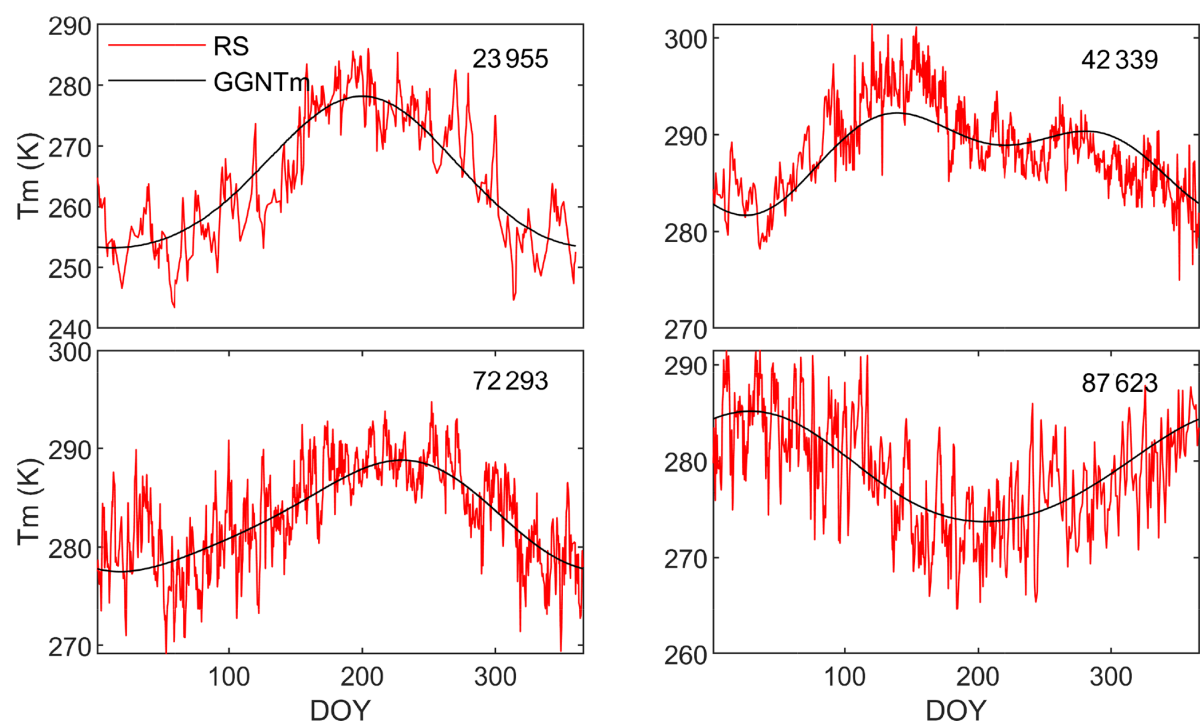

Figure 6. $T_{\mathrm{m}}$ values (at the earth surface) integrated from the radiosonde measurements as well as that predicted by GGNTm at each of the four radiosonde stations (nos. 23955, 42339,72293, and 87623).

data from ECMWF and NCEP (Chen et al., 2011; Decker et al., 2012). Compared to GTrop and GWMT_D, GGNTm performed very well at all pressure levels. This is because the model accounted for the vertical nonlinear variation in $T_{\mathrm{m}}$.

The results shown in Table 1 were the statistics of all global grid points at each of the five pressure levels selected. For more refined results, Fig. 5 shows the map for the RMSE of $T_{\mathrm{m}}$ at each grid point at either the 950 or $500 \mathrm{hPa}$ pressure levels resulting from three models. The $950 \mathrm{hPa}$ pressure level (Fig. 5a, c, e) results indicated that the RMSEs of $T_{\mathrm{m}}$ resulting from all the three models were latitude-dependent and high-accuracy $T_{\mathrm{m}}$ values (in blue) were mainly in lowlatitude belts. However, the results at the $500 \mathrm{hPa}$ pressure level (Fig. 5b, d, f) indicated that the new model significantly outperformed the other two models. In addition, from the $950 \mathrm{hPa}$ pressure level results, the percentages of those RMSE values that were under $5 \mathrm{~K}$ from all the global grid points for GTrop, GWMT_D, and GGNTm were 93.4\%, $82.1 \%$, and $94.6 \%$, respectively; while the corresponding percentage values at the $500 \mathrm{hPa}$ level were $44.9 \%, 70.6 \%$, and $88.7 \%$. These suggest that larger improvements made by the new model, i.e., GGNTm, over the other two models were at high-altitude pressure levels.

\subsection{Comparison with radiosonde data}

In this section, $T_{\mathrm{m}}$ from radiosonde profiles were used as the reference for the performance assessment of the models selected. The original radiosonde data at all globally distributed stations in 2018 were downloaded from the website of the University of Wyoming (http://weather.uwyo.edu/upperair/, last access: 13 March 2020). Different from the use of reanalysis data as the reference, water vapor pressure at each pres- sure level from a radiosonde profile was calculated through a mixing ratio:

$e=R p /(622+R)$,

where $R$ denotes the mixing ratio $(\mathrm{g} / \mathrm{kg})$.

An additional data pre-processing procedure needs to be conducted for data quality control. Those poor radiosonde profiles needed to be identified and excluded from their use for the reference. The first check was for a valid mixing ratio value: if a pressure level lacks a valid mixing ratio value, then it is regarded as invalid and thus to be excluded. After this initial checking was performed, further identifications were also carried out. A profile would be excluded if it met any one of the following four conditions:

1. the profile lacks surface meteorological observations;

2. the pressure value of the top pressure level is greater than $100 \mathrm{hPa}$;

3. the difference in the pressure values at two successive levels is under $200 \mathrm{hPa}$;

4. the profile consists of a few pressure levels; e.g., if $\Delta P / n \leq 30 \mathrm{hPa}$ (where $\Delta P$ is the difference of the pressure values at the surface and the $100 \mathrm{hPa}$ pressure levels and $n$ is the number of all pressure levels from the surface to the $100 \mathrm{hPa}$ pressure levels), then the profile was regarded to have sufficient number of pressure levels; otherwise it would be excluded from the use in the testing.

Sounding balloons are commonly launched twice a day (at 00:00 and 12:00 UTC). In this research, only those stations that had at least 300 profiles in 2018 were selected in 
Table 2. Mean bias and mean RMSE of $T_{\mathrm{m}}$ values at 428 globally distributed radiosonde stations in 2018 resulting from GPT3, GTrop, GWMT_D, and GGNTm.

\begin{tabular}{|c|c|c|c|c|c|}
\hline Height & Model & \multicolumn{2}{|c|}{ Bias (K) } & \multicolumn{2}{|c|}{ RMSE (K) } \\
\hline & GPT3 & $-0.36[-7.87$ & $5.81]$ & $3.97[1.36$ & $12.51]$ \\
\hline & GTrop & $0.16[-2.39$ & 4.23] & $3.87[1.35$ & $7.22]$ \\
\hline & GWMT_D & $1.30[-1.74$ & $5.64]$ & $4.07[1.51$ & 7.81] \\
\hline & GGNTm & $-0.34[-3.17$ & $3.74]$ & $3.89[1.39$ & $7.03]$ \\
\hline \multicolumn{6}{|c|}{ Under $10 \mathrm{~km}$} \\
\hline & GPT3 & $22.00[6.78$ & 27.29] & $27.67[10.80$ & 33.53] \\
\hline & GTrop & $1.50[-3.68$ & $5.97]$ & $5.08[1.90$ & $8.68]$ \\
\hline & GWMT_D & $1.16[-0.20$ & $6.18]$ & $4.61[2.24$ & $8.52]$ \\
\hline & GGNTm & $-0.16[-3.81$ & 4.69] & $4.20[1.37$ & 7.30] \\
\hline
\end{tabular}

Note: the values within square brackets are the minimum and maximum.

(a) RMSE of GTrop (surface)

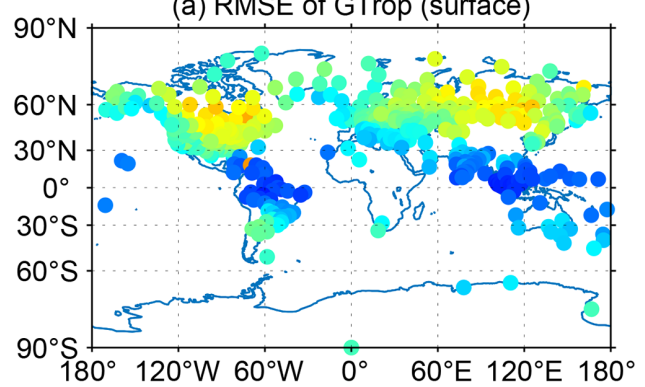

(c) RMSE of GWMT_D (surface)

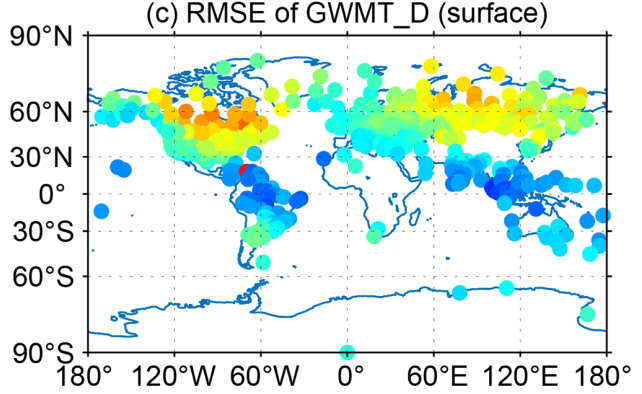

(e) RMSE of GGNTm (surface)

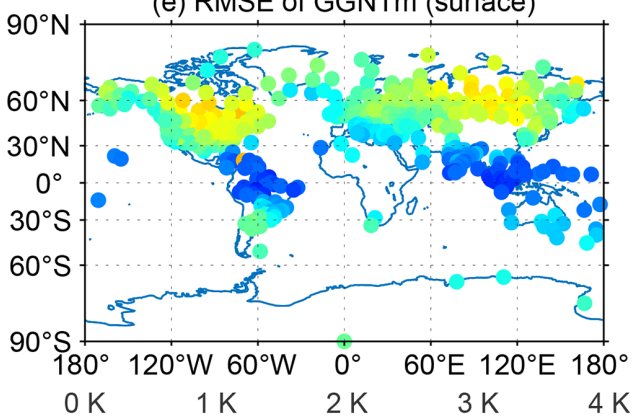

(b) RMSE of GTrop (under $10 \mathrm{~km}$ )

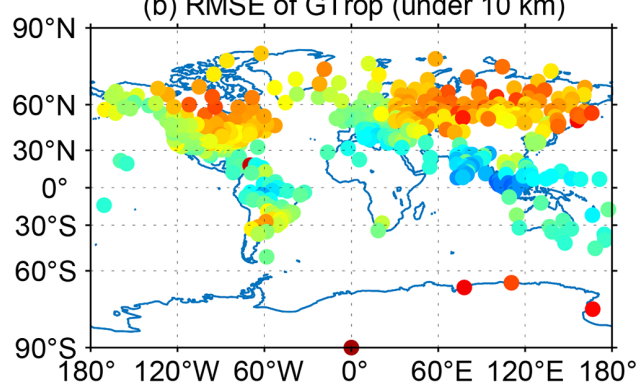

(d) RMSE of GWMT_D (under $10 \mathrm{~km}$ )
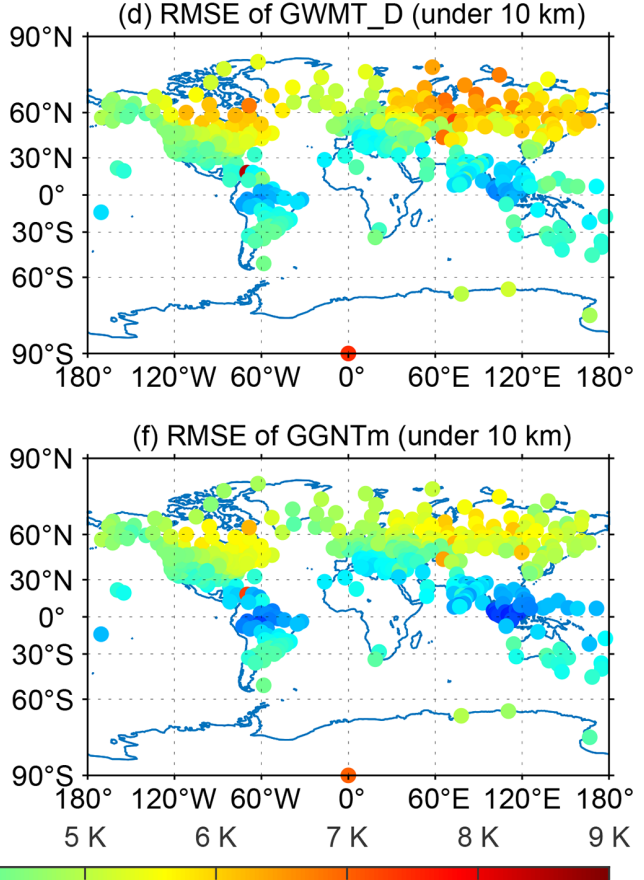

Figure 7. RMSE of $T_{\mathrm{m}}$ at surface level (a, c, e) and all pressure levels under $10 \mathrm{~km}(\mathbf{b}, \mathbf{d}, \mathbf{f})$ at each of the 428 radiosonde stations in 2018 resulting from GTrop, GWMT_D, and GGNTm. The RMSE of $T_{\mathrm{m}}$ under $10 \mathrm{~km}$ was calculated using the differences between modelpredicted $T_{\mathrm{m}}$ values and the $T_{\mathrm{m}}$ values over all pressure levels with a height of less than $10 \mathrm{~km}$. 
the model performance assessment. After the above five-step quality control procedure was performed, a total of 260140 profiles from 428 global radiosonde stations were finally used in the performance evaluation of three selected models. Figure 6 shows the $T_{\mathrm{m}}$ values (at the earth surface) integrated from the radiosonde measurements as well as that predicted by GGNTm at four radiosonde stations.

Table 2 shows the mean bias and RMSE of surface $T_{\mathrm{m}}$ values and $T_{\mathrm{m}}$ values at all pressure levels from the surface to $10 \mathrm{~km}$ height at all the aforementioned radiosonde stations resulting from each of the three models that were the same as the ones tested in the previous section. For the surface $T_{\mathrm{m}}$ results, the mean RMSE of GTrop and GGNTm were very close; GWMT_D was the worst, with the largest bias and RMSE values, which may be due to its low horizontal resolution $\left(5^{\circ} \times 5^{\circ}\right)$. The other set of results, the RMSE of $T_{\mathrm{m}}$ under $10 \mathrm{~km}$, was calculated using the differences between model-predicted $T_{\mathrm{m}}$ values and the reference $T_{\mathrm{m}}$ values over all pressure levels with a height of less than $10 \mathrm{~km}$. A small RMSE of $T_{\mathrm{m}}$ under $10 \mathrm{~km}$ indicates that the model performs well at any altitudes below the tropopause. As we can see, GWMT_D was slightly better than GTrop, possibly because the $T_{\mathrm{m}}$ value from the former was interpolated from the $T_{\mathrm{m}}$ values at four height levels; the mean bias of $T_{\mathrm{m}}$ from the new model, GGNTm, was the lowest, with the value of -0.16 , which was close to 0 , meaning nearly unbiased; the RMSE of the new model was also the lowest, among the three models, which suggests that the vertical nonlinear variation in $T_{\mathrm{m}}$ was modeled more accurately in the new model than in the other existing models.

Similar to Fig. 5, Fig. 7 shows the map for the RMSE of $T_{\mathrm{m}}$ values at each of the 428 radiosonde stations in 2018 at the surface pressure level (Fig. 5a, c, e) and all pressure levels with a height of less than $10 \mathrm{~km}$ (Fig. b, d, f) resulting from GTrop, GWMT_D, and GGNTm. It can be found that the RMSEs of all models were latitude-dependent, and those stations that had a large RMSE value were mostly located in north Africa and northeast America. At the four stations located in Antarctic, their surface $T_{\mathrm{m}}$ values were accurately modeled by these models. However, in terms of the RMSE of all pressure levels under $10 \mathrm{~km}$, the GTrop results were relatively large at the four stations, whilst both GWMT_D and GGNTm performed well at three of the stations.

To further evaluate the performance of the three models at different height ranges under $10 \mathrm{~km}$, the models' $T_{\mathrm{m}}$ values from the aforementioned radiosonde profiles at the 428 global stations were divided into five height ranges, and Fig. 8 shows each height range's bias and RMSE. We can see the following results: (1) in the height ranges above $4 \mathrm{~km}$, the GTrop results had the largest bias and largest RMSE, and GWMT_D was considerably better than GTrop; (2) in low height ranges the GWMT_D results were the worst; (3) in all height ranges the GGNTm results were nearly unbiased and their accuracy varied little with height. The GGNTm model's consistent high accuracy in all height ranges suggests that

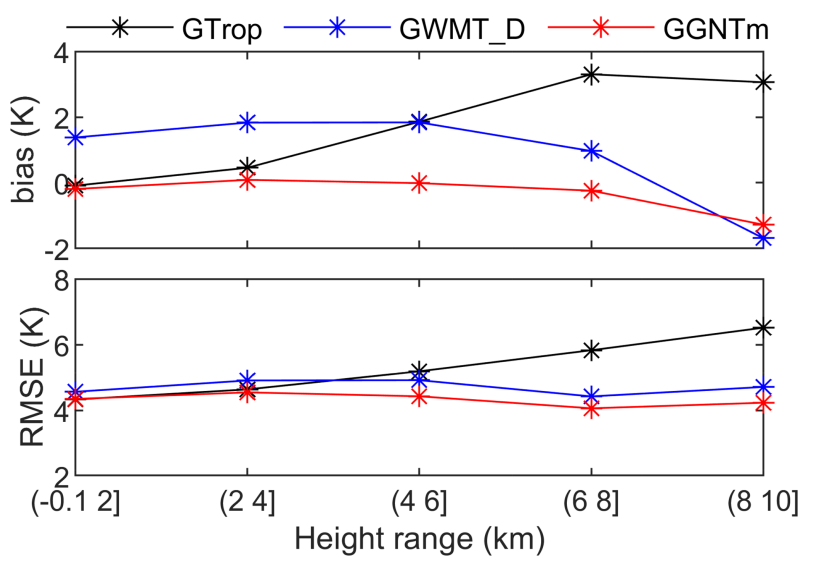

Figure 8. Bias and RMSE of $T_{\mathrm{m}}$ from radiosonde profiles at 428 global radiosonde stations in each of five height ranges resulting from GTrop, GWMT_D, and GGNTm.

the characteristics of the vertical nonlinear variation in $T_{\mathrm{m}}$ are modeled by the proposed model more accurately than the other models.

\subsection{Evaluation of GGNTm under extreme weather conditions}

The performance of our model under extreme weather conditions has also been assessed. The $T_{\mathrm{m}}$ values integrated from the radiosonde profiles at KingsPark radiosonde station (no. 45005, Hong Kong) from August to September in 2018 (summer storm period) were taken as the reference data in this research. As is shown in Fig. 9, the $T_{\mathrm{m}}$ values at the station predicted by GGNTm as well as a $T_{\mathrm{m}}-T_{\mathrm{s}}$ model $\left(T_{\mathrm{m}}=0.6195 \times T_{\mathrm{s}}+103.3452\right)$ developed using $T_{\mathrm{m}}$ and $T_{\mathrm{s}}$ series at KingsPark station (He et al., 2019) were compared against corresponding radiosonde measurements during the summer storm period. The daily total rainfall data (published by Hong Kong Observatory, https://www.hko.gov.hk, last access: 2 December 2020) during the 2 months are also shown in the figure. Heavy rainfall occurred frequently in Hong Kong during the 2 months, and a super typhoon, named Mangkhut, landed near Hong Kong and caused torrential rain on 16 September. As is shown in the figure, our model shows clear outperformance during the 2 months compared to the $T_{\mathrm{m}}-T_{\mathrm{s}}$ model. More experiments showed that the coefficients of $T_{\mathrm{m}}-T_{\mathrm{s}}$ models vary significantly with time (i.e., $0.6195 \mathrm{vs}$. 0.58 for the linear part and 103.3452 vs. 115.71 for the constant part, respectively), which means that a $T_{\mathrm{m}}-T_{\mathrm{s}}$ model that is based on the linear regression may have large errors during some periods.

\subsection{Impact of GGNTm on PWV}

The accuracy of GNSS-PWV over a GNSS site at an observing time is dependent upon the accuracies of the ZWD and the conversion factor. Uncertainty analysis has been con- 

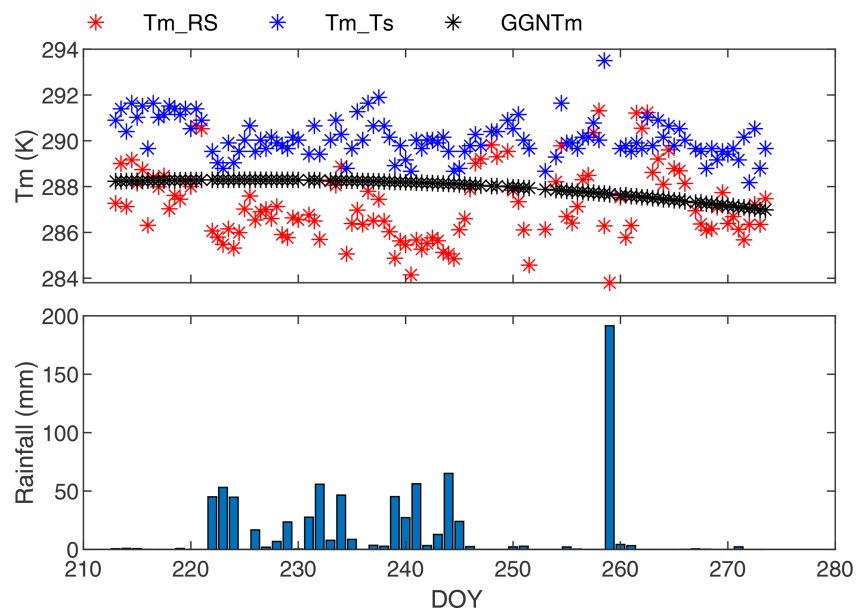

Figure 9. $T_{\mathrm{m}}$ derived from radiosonde profiles, the $T_{\mathrm{m}}-T_{\mathrm{S}}$ model, GGNTm from August to September in 2018 at KingsPark station, and the daily total rainfall at Hong Kong International Airport.

ducted by some researchers to study the uncertainty of the GNSS-derived PWV resulting from different variables, including the uncertainty of GNSS-ZTD, the atmospheric pressure, the $T_{\mathrm{m}}$, and other constants utilized (Jiang et al., 2019b; Ning et al., 2016). This section mainly focuses on the impact of the newly developed $T_{\mathrm{m}}$ model on PWV; however, it is difficult to evaluate the impact of $T_{\mathrm{m}}$ on the GNSS-PWV directly. In this research, the ZWD and $T_{\mathrm{m}}$ derived from the ERA5 hourly reanalysis (the same as the data utilized in Sect. 3.1) were used for simulating the GNSS-PWV sensing. The ZWDs at each of the pressure levels over the globally distributed grid points (2664 grid points in total) were calculated through integration:

$\mathrm{ZWD}=10^{-6} \int_{H}^{\infty}\left(k_{2}^{\prime} \frac{e}{T}+k_{3} \frac{e}{T^{2}}\right) \mathrm{d} h$,

where $H$ is the height of the reference pressure level. Then the reference PWVs can be obtained using the ZWDs and the corresponding conversion factors resulting from the reference $T_{\mathrm{m}}$ values, as is shown in Eq. (1). Similarly, the PWVs resulting from different empirical $T_{\mathrm{m}}$ models can be obtained. The statistical results of the RMSEs of the PWVs resulting from different model-predicted $T_{\mathrm{m}}$ values by comparing the PWVs resulting from the reference $T_{\mathrm{m}}$ values (as references) are shown in Fig. 10. As we can see, the performance of both GGNTm and GTrop were better than GWMT_D. The mean RMSE of the predicted PWVs resulting from GTrop and GGNTm over 2664 grid points were approximately the same. But the maximum RMSE of the PWVs resulting from GGNTm were better than GTrop from 1000 to $775 \mathrm{hPa}$. This is because the nonlinear variation in $T_{\mathrm{m}}$ in the vertical direction was properly modeled in some regions. We can also find that there are not significant differences between the RMSEs of the predicted PWVs resulting from GGNTm and GTrop due to less water vapor at the pressure levels with

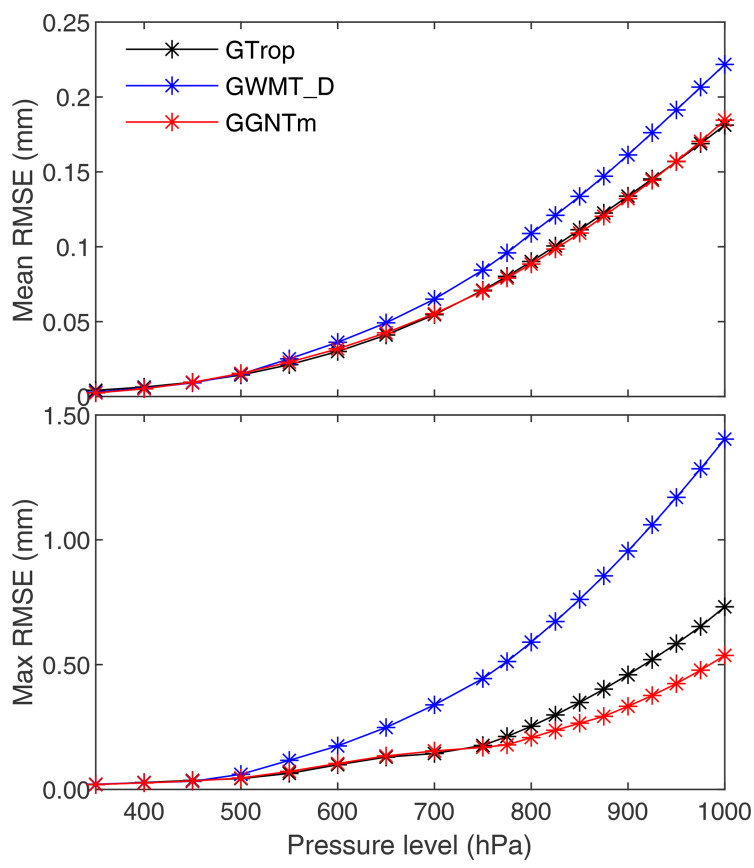

Figure 10. Mean RMSE and maximum RMSE of PWV values at each of the pressure levels at 12:00 UTC at all global grid points in 2018 resulting from each of the three models selected.

high altitudes, although the accuracy of the model-predicted $T_{\mathrm{m}}$ values resulting from GGNTm was better than GTrop. However, due to the fact that the water vapor content varies with latitude, terrain, season, and weather, the improvement in the model-predicted $T_{\mathrm{m}}$ values at pressure levels with high altitudes is still meaningful.

\section{Conclusions}

In GNSS meteorology, $T_{\mathrm{m}}$ is an essential parameter for converting GNSS-ZWD to PWV over the GNSS observing station. In practice, the $T_{\mathrm{m}}$ value over a GNSS station at an observing time is commonly obtained from an empirical $T_{\mathrm{m}}$ model, such as GPT3, GTrop, and GWMT_D. In this research, a new global gridded empirical $T_{\mathrm{m}}$ model, named GGNTm, was developed. In this model, the vertical nonlinear variation in $T_{\mathrm{m}}$ was modeled using a three-order polynomial function fitting ERA5 monthly mean reanalysis data over the 10-year period from 2008 to 2017; and seasonal variation terms, including mean, annual, and semi-annual amplitudes, for each of the coefficients in the polynomial function at each of global grid points were also modeled based on the 10 -year time series of the coefficient.

The performance of the newly developed GGNTm model was assessed and compared with GTrop and GWMT using model-predicted $T_{\mathrm{m}}$ values in 2018 against two references in the same year: (1) $T_{\mathrm{m}}$ from ERA5 hourly reanalysis data and (2) $T_{\mathrm{m}}$ from radiosonde profiles at 428 global radiosonde 
stations. Compared to the first reference, the RMSEs of $T_{\mathrm{m}}$ values resulting from GGNTm at five pressure levels over all the global grid points in 2018 were significantly smaller than those of the other three models at high-altitude pressure levels. Compared to the second reference, the mean bias and mean RMSE of $T_{\mathrm{m}}$ resulting from GGNTm at all the 428 radiosonde stations in 2018 were 0.34 and $3.89 \mathrm{~K}$, respectively; and the mean bias and mean RMSE of $T_{\mathrm{m}}$ resulting from GGNTm at all pressure levels from the surface to $10 \mathrm{~km}$ height were 0.16 and $4.20 \mathrm{~K}$, respectively, which was significantly smaller than those of all the other three models. In all five height ranges from the surface to $10 \mathrm{~km}$ in altitude, the GGNTm results were nearly unbiased, and their accuracy varied little with height. This result suggests that the characteristics of the vertical nonlinear variation in $T_{\mathrm{m}}$ is modeled by the approach proposed in this study more accurately than the existing models. In addition, the impact of GGNTm on GNSS-PWV was analyzed. The results showed that the accuracy of the PWV resulting from GGNTm outperformed the GTrop and GWMT models.

The improvement in the accuracy of the new $T_{\mathrm{m}}$ model has significance for both long-term GNSS-PWV analysis and NRT/RT GNSS-PWV sensing. Our future work will be focusing on using high temporal-resolution atmospheric data such as ERA5 hourly reanalysis data, instead of monthly mean data used in this study, to model the temporal variation in the coefficients in the $T_{\mathrm{m}}$ fitting function for further improving the accuracy of the GGNTm model.

Data availability. ERA5 monthly mean data are available here: https://doi.org/10.24381/cds.6860a573 (Hersbach et al., 2019). ERA5 hourly data are available here: https://doi.org/10.24381/cds.bd0915c6 (Hersbach et al., 2018).

Radiosonde data are provided by the University of Wyoming via http://weather.uwyo.edu/upperair/sounding.html (last access: 13 March 2020, University of Wyoming, 2020).

Supplement. The supplement related to this article is available online at: https://doi.org/10.5194/amt-14-2529-2021-supplement.

Author contributions. PS designed the experiments and wrote the original draft. SW and KZ reviewed and revised the paper. MW and RW processed the ERA5 reanalysis data and radiosonde data.

Competing interests. The authors declare that they have no conflict of interest.

Acknowledgements. We would like to thank the ECMWF and the University of Wyoming for providing ERA5 reanalysis data and radiosonde profiles, respectively.
Financial support. This research has been supported by the National Natural Science Foundation of China (grant nos. 41730109 and 41874040), the Xuzhou Key Project (grant no. KC19111), and the Jiangsu dual creative talents and Jiangsu dual creative teams program projects of Jiangsu Province, China, awarded in 2017.

Review statement. This paper was edited by Roeland Van Malderen and reviewed by Maohua Ding and one anonymous referee.

\section{References}

Askne, J. and Nordius, H.: Estimation of tropospheric delay for microwaves from surface weather data, Radio Sci., 22, 379-386, https://doi.org/10.1029/RS022i003p00379, 1987.

Bennitt, G. V. and Jupp, A.: Operational Assimilation of GPS Zenith Total Delay Observations into the Met Office Numerical Weather Prediction Models, Mon. Weather Rev., 140, 27062719, https://doi.org/10.1175/MWR-D-11-00156.1, 2012.

Bevis, M.: GPS meteorology: mapping zenith wet delays onto precipitable water, J. Appl. Meteorol., 33, 379-386, https://doi.org/10.1175/15200450(1994)033<0379:GMMZWD>2.0.CO;2, 1994.

Bevis, M., Businger, S., Herring, T. A., Rocken, C., Anthes, R. A., and Ware, R. H.: GPS meteorology: remote sensing of atmospheric water vapor using the global positioning system, J. Geophys. Res., 97, 787-801, https://doi.org/10.1029/92jd01517, 1992.

Bianchi, C. E., Mendoza, L. P. O., Fernández, L. I., Natali, M. P., Meza, A. M., and Moirano, J. F.: Multi-year GNSS monitoring of atmospheric IWV over Central and South America for climate studies, Ann. Geophys., 34, 623-639, https://doi.org/10.5194/angeo-34-623-2016, 2016.

Böhm, J., Möller, G., Schindelegger, M., Pain, G., and Weber, R.: Development of an improved empirical model for slant delays in the troposphere (GPT2w), GPS Solut., 19, 433-441, https://doi.org/10.1007/s10291-014-0403-7, 2015.

Bonafoni, S. and Biondi, R.: The usefulness of the Global Navigation Satellite Systems (GNSS) in the analysis of precipitation events, Atmos. Res., 167, 15-23, https://doi.org/10.1016/j.atmosres.2015.07.011, 2016.

Calori, A., Santos, J. R., Blanco, M., Pessano, H., Llamedo, P., Alexander, P., and de la Torre, A.: Ground-based GNSS network and integrated water vapor mapping during the development of severe storms at the Cuyo region (Argentina), Atmos. Res., 176/177, 267-275, https://doi.org/10.1016/j.atmosres.2016.03.002, 2016.

Chen, B., Dai, W., Liu, Z., Wu, L., Kuang, C., and Ao, M.: Constructing a precipitable water vapor map from regional GNSS network observations without collocated meteorological data for weather forecasting, Atmos. Meas. Tech., 11, 5153-5166, https://doi.org/10.5194/amt-11-5153-2018, 2018.

Chen, Q., Song, S., Heise, S., Liou, Y.-A., Zhu, W., and Zhao, J.: Assessment of ZTD derived from ECMWF/NCEP data with GPS ZTD over China, GPS Solut., 15, 415-425, https://doi.org/10.1007/s10291-010-0200-x, 2011.

Choy, S., Wang, C., Zhang, K., and Kuleshov, Y.: GPS sensing of precipitable water vapour during the March 
2010 Melbourne storm, Adv. Space Res., 52, 1688-1699, https://doi.org/10.1016/j.asr.2013.08.004, 2013.

Davis, J. L., Herring, T. A., Shapiro, I. I., Rogers, A. E. E., and Elgered, G.: Geodesy by radio interferometry: Effects of atmospheric modeling errors on estimates of baseline length, Radio Sci., 20, 1593-1607, https://doi.org/10.1029/RS020i006p01593, 1985.

Decker, M., Brunke, M. A., Wang, Z., Sakaguchi, K., Zeng, X., and Bosilovich, M. G.: Evaluation of the Reanalysis Products from GSFC, NCEP, and ECMWF Using Flux Tower Observations, J. Climate, 25, 1916-1944, https://doi.org/10.1175/JCLI-D-1100004.1, 2012.

Ding, M.: A neural network model for predicting weighted mean temperature, J. Geodesy, 92, 1187-1198, https://doi.org/10.1007/s00190-018-1114-6, 2018.

Ding, M.: A second generation of the neural network model for predicting weighted mean temperature, GPS Solut., 24, 61, https://doi.org/10.1007/s10291-020-0975-3, 2020.

Ding, W., Teferle, F. N., Kazmierski, K., Laurichesse, D., and Yuan, Y.: An evaluation of real-time troposphere estimation based on GNSS Precise Point Positioning, J. Geophys. Res., 122, 27792790, https://doi.org/10.1002/2016JD025727, 2017.

Dousa, J. and Elias, M.: An improved model for calculating tropospheric wet delay, Geophys. Res. Lett., 41, 4389-4397, https://doi.org/10.1002/2014GL060271, 2014.

Dousa, J. and Vaclavovic, P.: Real-time zenith tropospheric delays in support of numerical weather prediction applications, Adv. Space Res., 53, 1347-1358, https://doi.org/10.1016/j.asr.2014.02.021, 2014.

Douša, J., Dick, G., Kačmařík, M., Brožková, R., Zus, F., Brenot, H., Stoycheva, A., Möller, G., and Kaplon, J.: Benchmark campaign and case study episode in central Europe for development and assessment of advanced GNSS tropospheric models and products, Atmos. Meas. Tech., 9, 2989-3008, https://doi.org/10.5194/amt-9-2989-2016, 2016.

Fan, S.-J., Zang, J.-F., Peng, X.-Y., Wu, S.-Q., Liu, Y.-X., and Zhang, K.-F.: Validation of Atmospheric Water Vapor Derived from Ship-Borne GPS Measurements in the Chinese Bohai Sea, Terr. Atmos. Ocean. Sci., 27, 213-220, https://doi.org/10.3319/TAO.2015.11.04.01(A), 2016.

Guerova, G., Jones, J., Douša, J., Dick, G., de Haan, S., Pottiaux, E., Bock, O., Pacione, R., Elgered, G., Vedel, H., and Bender, M.: Review of the state of the art and future prospects of the groundbased GNSS meteorology in Europe, Atmos. Meas. Tech., 9, 5385-5406, https://doi.org/10.5194/amt-9-5385-2016, 2016.

He, C., Wu, S., Wang, X., Hu, A., Wang, Q., and Zhang, K.: A new voxel-based model for the determination of atmospheric weighted mean temperature in GPS atmospheric sounding, Atmos. Meas. Tech., 10, 2045-2060, https://doi.org/10.5194/amt10-2045-2017, 2017.

He, Q., Zhang, K., Wu, S., Zhao, Q., Wang, X., Shen, Z., Li, L., Wan, M., and Liu, X.: Real-Time GNSS-Derived PWV for Typhoon Characterizations: A Case Study for Super Typhoon Mangkhut in Hong Kong, Remote Sens., 12, 104, https://doi.org/10.3390/rs12010104, 2019.

Hersbach, H., Bell, B., Berrisford, P., Biavati, G., Horányi, A., Muñoz Sabater, J., Nicolas, J., Peubey, C., Radu, R., Rozum, I., Schepers, D., Simmons, A., Soci, C., Dee, D., and Thépaut, J.N.: ERA5 hourly data on pressure levels from 1979 to present,
Copernicus Climate Change Service (C3S) Climate Data Store (CDS), https://doi.org/10.24381/cds.bd0915c6, 2018.

Hersbach, H., Bell, B., Berrisford, P., Biavati, G., Horányi, A., Muñoz Sabater, J., Nicolas, J., Peubey, C., Radu, R., Rozum, I., Schepers, D., Simmons, A., Soci, C., Dee, D., and Thépaut, J.N.: ERA5 monthly averaged data on pressure levels from 1979 to present, Copernicus Climate Change Service (C3S) Climate Data Store (CDS), https://doi.org/10.24381/cds.6860a573, 2019.

Huang, L., Jiang, W., Liu, L., Chen, H., and Ye, S.: A new global grid model for the determination of atmospheric weighted mean temperature in GPS precipitable water vapor, J. Geodesy, 93, 159-176, https://doi.org/10.1007/s00190-018-1148-9, 2019a.

Huang, L., Liu, L., Chen, H., and Jiang, W.: An improved atmospheric weighted mean temperature model and its impact on GNSS precipitable water vapor estimates for China, GPS Solut., 23, 51, https://doi.org/10.1007/s10291-019-0843-1, 2019b.

Jiang, P., Ye, S., Lu, Y., Liu, Y., Chen, D., and Wu, Y.: Development of time-varying global gridded $T_{\mathrm{S}}-T_{\mathrm{m}}$ model for precise GPS-PWV retrieval, Atmos. Meas. Tech., 12, 1233-1249, https://doi.org/10.5194/amt-12-1233-2019, 2019a.

Jiang, P., Ye, S., Lu, Y., Liu, Y., Chen, D., and Wu, Y.: Development of time-varying global gridded $\mathrm{T}_{\mathrm{S}}-T_{\mathrm{m}}$ model for precise GPS-PWV retrieval, Atmos. Meas. Tech., 12, 1233-1249, https://doi.org/10.5194/amt-12-1233-2019, 2019b.

Landskron, D. and Böhm, J.: VMF3/GPT3: refined discrete and empirical troposphere mapping functions, J. Geodesy, 92, 349-360, https://doi.org/10.1007/s00190-017-1066-2, 2018.

Le Marshall, J., Xiao, Y., Norman, R., Zhang, K., Rea, A., Cucurull, L., Seecamp, R., Steinle, P., Puri, K., Fu, E., and Le, T.: The application of radio occultation observations for climate monitoring and numerical weather prediction in the Australian region, Aust. Meteorol. Ocean., 62, 323-334, https://doi.org/10.22499/2.6204.010, 2012.

Le Marshall, J., Norman, R., Howard, D., Rennie, S., Moore, M., Kaplon, J., Xiao, Y., Zhang, K., Wang, C., Cate, A., Lehmann, P., Wang, X., Steinle, P., Tingwell, C., Le, T., Rohm, W., and Ren, D.: Using GNSS Data for Real-time Moisture Analysis and Forecasting over the Australian Region I. The System, Journal of Southern Hemisphere Earth System Science, 69, 1-21, https://doi.org/10.22499/3.6901.009, 2019.

Li, Q., Yuan, L., Chen, P., and Jiang, Z.: Global grid-based $T_{\mathrm{m}}$ model with vertical adjustment for GNSS precipitable water retrieval, GPS Solut., 24, 73, https://doi.org/10.1007/s10291-02000988-x, 2020.

Li, X., Dick, G., Lu, C., Ge, M., Nilsson, T., Ning, T., Wickert, J., and Schuh, H.: Multi-GNSS Meteorology: Real-Time Retrieving of Atmospheric Water Vapor from BeiDou, Galileo, GLONASS, and GPS Observations, IEEE T. Geosci. Remote, 53, 6385-6393, https://doi.org/10.1109/TGRS.2015.2438395, 2015.

Lu, C., Li, X., Nilsson, T., Ning, T., Heinkelmann, R., Ge, M., Glaser, S., and Schuh, H.: Real-time retrieval of precipitable water vapor from GPS and BeiDou observations, J. Geodesy, 89, 843-856, https://doi.org/10.1007/s00190-015-0818-0, 2015.

Nafisi, V., Urquhart, L., Santos, M. C., Nievinski, F. G., Böhm, J., Wijaya, D. D., Schuh, H., Ardalan, A. A., Hobiger, T., Ichikawa, R., Zus, F., Wickert, J., and Gegout, P.: Comparison of ray-tracing packages for troposphere delays, IEEE T. Geosci. Remote, 50, 469-481, https://doi.org/10.1109/TGRS.2011.2160952, 2012. 
Ning, T., Wang, J., Elgered, G., Dick, G., Wickert, J., Bradke, M., Sommer, M., Querel, R., and Smale, D.: The uncertainty of the atmospheric integrated water vapour estimated from GNSS observations, Atmos. Meas. Tech., 9, 79-92, https://doi.org/10.5194/amt-9-79-2016, 2016.

Rohm, W., Yuan, Y., Biadeglgne, B., Zhang, K., and Marshall, J. L.: Ground-based GNSS ZTD/IWV estimation system for numerical weather prediction in challenging weather conditions, Atmos. Res., 138, 414-426, https://doi.org/10.1016/j.atmosres.2013.11.026, 2014a.

Rohm, W., Yuan, Y., Biadeglgne, B., Zhang, K., and Le Marshall, J.: Ground-based GNSS ZTD/IWV estimation system for numerical weather prediction in challenging weather conditions, Atmos. Res., 138, 414-426, https://doi.org/10.1016/j.atmosres.2013.11.026, 2014b.

Shi, J., Chaoqian, X., Jiming, G., and Yang, G.: RealTime GPS Precise Point Positioning-Based Precipitable Water Vapor Estimation for Rainfall Monitoring and Forecasting, IEEE T. Geosci. Remote, 53, 3452-3459, https://doi.org/10.1109/TGRS.2014.2377041, 2015.

Sun, Z., Zhang, B., and Yao, Y.: A global model for estimating tropospheric delay and weighted mean temperature developed with atmospheric reanalysis data from 1979 to 2017, Remote Sens., 11, 1893, https://doi.org/10.3390/rs11161893, 2019.

University of Wyoming: Radiosonde data, avaialable at: http:// weather.uwyo.edu/upperair/sounding.html, last access: 13 March 2020.

Wang, J., Zhang, L., and Dai, A.: Global estimates of water-vapor-weighted mean temperature of the atmosphere for GPS applications, J. Geophys. Res.-Atmos., 110, 1-17, https://doi.org/10.1029/2005JD006215, 2005.

Wang, J., Wu, Z., Semmling, M., Zus, F., Gerland, S., Ramatschi, M., Ge, M., Wickert, J., and Schuh, H.: Retrieving Precipitable Water Vapor From Shipborne MultiGNSS Observations, Geophys. Res. Lett., 46, 5000-5008, https://doi.org/10.1029/2019GL082136, 2019.

Wang, X., Zhang, K., Wu, S., Fan, S., and Cheng, Y.: Water vaporweighted mean temperature and its impact on the determination of precipitable water vapor and its linear trend, J. Geophys. Res.Atmos., 121, 833-852, https://doi.org/10.1002/2015JD024181, 2016.

Wang, X., Zhang, K., Wu, S., Li, Z., Cheng, Y., Li, L., and Yuan, H.: The correlation between GNSS-derived precipitable water vapor and sea surface temperature and its responses to El Niño-Southern Oscillation, Remote Sens. Environ., 216, 1-12, https://doi.org/10.1016/j.rse.2018.06.029, 2018.
Webb, S. R., Penna, N. T., Clarke, P. J., Webster, S., Martin, I., and Bennitt, G. V.: Kinematic GNSS Estimation of Zenith Wet Delay over a Range of Altitudes, J. Atmos. Ocean. Technol., 33, 3-15, https://doi.org/10.1175/JTECH-D-14-00111.1, 2016.

Yang, F., Meng, X., Guo, J., Shi, J., An, X., He, Q., and Zhou, L.: The Influence of different modelling factors on Global temperature and pressure models and their performance in different zenith hydrostatic delay (ZHD) models, Remote Sens., 12, 35, https://doi.org/10.3390/RS12010035, 2020.

Yao, Y., Zhu, S., and Yue, S. Q.: A globally applicable, season-specific model for estimating the weighted mean temperature of the atmosphere, J. Geodesy, 86, 1125-1135, https://doi.org/10.1007/s00190-012-0568-1, 2012.

Yao, Y., Zhang, B., Yue, S. Q., Xu, C. Q., and Peng, W. F.: Global empirical model for mapping zenith wet delays onto precipitable water, J. Geodesy, 87, 439-448, https://doi.org/10.1007/s00190013-0617-4, 2013.

Yao, Y., Zhang, B., Xu, C., and Chen, J.: Analysis of the global $T_{\mathrm{m}}-T_{\mathrm{S}}$ correlation and establishment of the latituderelated linear model, Chinese Sci. Bull., 59, 2340-2347, https://doi.org/10.1007/s11434-014-0275-9, 2014a.

Yao, Y., Xu, C., Zhang, B., and Cao, N.: GTm-III: A new global empirical model for mapping zenith wet delays onto precipitable water vapour, Geophys. J. Int., 197, 202-212, https://doi.org/10.1093/gji/ggu008, 2014b.

Yao, Y., Sun, Z., Xu, C., Xu, X., and Kong, J.: Extending a model for water vapor sounding by ground-based GNSS in the vertical direction, J. Atmos. Sol.-Terr. Phy., 179, 358-366, https://doi.org/10.1016/j.jastp.2018.08.016, 2018.

Yuan, Y., Zhang, K., Rohm, W., Choy, S., Norman, R., and Wang, C.: Real-time retrieval of precipitable water vapor from GPS precise point positioning, J. Geophys. Res.-Atmos., 119, 1004410057, https://doi.org/10.1002/2014JD021486, 2014.

Zhang, K., Manning, T., Wu, S., Rohm, W., Silcock, D., and Choy, S.: Capturing the Signature of Severe Weather Events in Australia Using GPS Measurements, IEEE J. Sel. Top. Appl., 8, 1839-1847, https://doi.org/10.1109/JSTARS.2015.2406313, 2015.

Zhou, F., Cao, X., Ge, Y., and Li, W.: Assessment of the positioning performance and tropospheric delay retrieval with precise point positioning using products from different analysis centers, GPS Solut., 24, 12, https://doi.org/10.1007/s10291-019-0925-0, 2020. 